\title{
Employment Quota System and Labour Market Outcomes of Individuals with Disabilities: Empirical Evidence from South Korea*
}

\author{
ZAFAR NAZAROV,$\dagger$ DONGUG KANG + and SARAH VON \\ SCHRADER $\S$
}

$\dagger$ Indiana University-Purdue University Fort Wayne; Employment and Disability Institute, Cornell University

(nazarovz@ipfw.edu)

$\$$ Korea National University of Welfare

(kdongug@gmail.com)

\$Employment and Disability Institute, Cornell University

(sv282@cornell.edu)

\begin{abstract}
To date, only a few studies have attempted to evaluate the effectiveness of disability employment quota systems using structural changes in policies. This study exploits the structural changes in South Korea's disability employment quota system that took place in 2004 and 2006 to expand the current disability policy evaluation literature. We separate the effect of these changes in the quota system into their effect on the probability of labour force participation and their effect on the probability of employment (after controlling for selection into the labour market). We also study the extent to which the changes - which included increasing the number of employers covered by the quota system, the number of jobs available to individuals
\end{abstract}

*Submitted November 2013

This study has been funded in part by the K. Lisa Yang Gift Fund to the Employment and Disability Institute in the Cornell University ILR (Industrial and Labor Relations) School.

Keywords: disability employment quota system, labour market, disability, labour force participation, employment, job satisfaction, binary response model with sample selection.

JEL classification numbers: J2, J7, J28, J48.

(C) 2015 Institute for Fiscal Studies

Fiscal Studies (C) 2015 Institute for Fiscal Studies. Published by John Wiley \& Sons Ltd, 9600 Garsington Road, Oxford, OX4 2DQ, UK, and 350 Main Street, Malden, MA 02148, USA. 
with disabilities and the financial incentives for employing individuals with disabilities - have affected job satisfaction among individuals with disabilities. Our results suggest that the changes in the quota system may have increased labour force participation but have had a limited positive impact on the probability of employment among people with disabilities in South Korea. Further, compulsory hiring and expanded opportunities have not substantially affected the level of job satisfaction observed among employees with disabilities relative to their non-disabled counterparts.

\section{Policy points}

- Using the structural changes in South Korea's disability employment quota system between 2004 and 2006 targeted at increasing the number of employers covered by the quota system, the number of jobs available to individuals with disabilities and the financial incentives for employing individuals with disabilities, we investigate the effect of new policy initiatives on various labour market outcomes of the targeted group of individuals relative to non-disabled counterparts.

- Our results suggest that the new initiatives may have increased labour force participation but have had a limited positive impact on the probability of employment among people with disabilities in South Korea.

- The new initiatives have not substantially affected the level of job satisfaction observed among employees with disabilities relative to their non-disabled counterparts.

- As the US and other developed countries consider their own disability employment situations, they can learn from studies such as this one on the effectiveness of quota systems.

\section{Introduction}

In the US, approximately 11 per cent of the federal budget is directed to agencies, departments and other entities to support disability services and income maintenance for individuals with disabilities. ${ }^{1}$ Although the greatest proportion of these funds in the US (about 85 per cent) is allocated to longterm care, health care and income maintenance, around 15 per cent is dedicated to various educational and training activities targeted at getting individuals with disabilities into competitive employment. Despite distributing vast monetary resources to such programmes, many developed societies, including the US, have insufficient labour force attachment among the segment of the population with disabilities. For example, in the US, the

${ }^{1}$ Braddock, 2010.

C) 2015 Institute for Fiscal Studies

Fiscal Studies @ 2015 Institute for Fiscal Studies 
employment rate among individuals with disabilities is more than 42 percentage points lower than that for individuals without disabilities. ${ }^{2}$ The story is similar in other Organisation for Economic Cooperation and Development (OECD) member countries, where employment rates for people with disabilities are, on average, just above 40 per cent, about half of the rate for people without a disability. ${ }^{3}$

To improve the labour market situation of individuals with disabilities, most developed societies have introduced a variety of employment policies directed at enhancing the participation of individuals with disabilities in the labour force. These policies can be broken down into two main types. The first type is policies that introduce quota systems obligating employers of a certain size to have a workforce with a certain percentage of individuals with disabilities. For example, Austria, Germany and South Korea use employment quotas as a means to improve labour market outcomes of individuals with disabilities. The second type of disability employment policies is anti-discriminatory laws, which do not directly incentivise employers to hire and retain individuals with disabilities, but instead are intended to eliminate employment discrimination. These anti-discrimination laws typically prohibit discrimination in hiring, firing, wages and other parts of the employment process and require employers to provide reasonable accommodations to qualified individuals with disabilities to facilitate their labour market attachment. Laws that prohibit employers from making hiring or employment decisions based on the presence of disability were adopted in the early 1990 s by a number of developed countries such as Australia, New Zealand and the US. Several countries, including South Korea, have implemented both of these types of policies.

A large body of literature has attempted to evaluate the effectiveness of these different types of disability employment policies. ${ }^{4}$ In the current literature, there is mixed evidence on the relative effectiveness of these policy initiatives. For example, one group of studies $^{5}$ found that the enactment of the Americans with Disabilities Act of 1990 (ADA), the antidiscrimination law in the US, led to a substantial decline in the employment rate for individuals with disabilities compared with their non-disabled peers. Theoretically, we can explain the negative effect by the strict requirement of reasonable accommodation or non-discrimination in wages, which may have inadvertently increased employer costs related to employing individuals with disabilities, presumably decreasing the hiring rate. That is, employers may have become concerned that hiring people with disabilities will require

${ }^{2}$ Erickson, Lee and von Schrader, 2012.

${ }^{3} \mathrm{OECD}, 2009$.

${ }^{4}$ For example, DeLeire (2000), Acemoglu and Angrist (2001), Beegle and Stock (2003), Kruse and Schur (2003), Lechner and Vazquez-Alvarez (2003), Hotchkiss (2004), Verick (2004), Bell and Heitmueller (2005), Lalive, Wuellrich and Zweimüller (2009), Wuellrich (2010) and Ryu et al. (2010).

${ }^{5}$ DeLeire, 2000; Acemoglu and Angrist, 2001. 
expensive workplace accommodations and/or employing people who cannot achieve productivity standards for particular jobs. Furthermore, the requirement of non-discrimination in firing may have increased the costs associated with hiring workers with disabilities. Jolls and Prescott (2004) estimated the effect of different components of the legislation on employment and found that the reasonable accommodation requirement may have been a main source of a decline in employment among individuals with disabilities in the first years after the enactment of the ADA, rather than prohibitions against discrimination in wages, hiring, firing and promotion. However, a more recent group of studies ${ }^{6}$ demonstrated that the enactment of the ADA was not a source of decline in the employment rate among people with disabilities. In fact, Hotchkiss (2004) uncovered that the unconditional probability of employment among individuals with disabilities (after controlling for selection into the labour market) had not declined after the enactment of the ADA, and may have actually improved for certain groups of individuals with disabilities.

To date, only a few studies have attempted to evaluate the effectiveness of employment quota systems using structural changes in employment policies. Conceptually, we expect that an increase in the level of penalty/ subsidy or a decrease in the minimum employer size incentivises employers to hire and retain more workers with disabilities in the workplace, since the marginal benefit of hiring and retaining a disabled worker increases after the expansion of the quota system. Further, a decrease in the minimum employer size to be covered by the quota leads to additional employment opportunities for people with disabilities. Verick (2004) evaluated the 2001 disability employment reform in Germany that decreased the quota rate by 1 percentage point (from 6 per cent to 5 per cent) and increased the minimum employer size covered by the law from 16 to 20 workers. The study found the changes in the quota system in Germany had no impact on the employment rate of individuals with severe disabilities. In Austria, in 2001, the penalty for not complying with the quota rate was increased by almost 30 per cent. Wuellrich (2010) found that this increase in penalty considerably increased firms' demand for disabled workers. Somewhat similar results for the same tax initiative in Austria were reported by Lalive, Wuellrich and Zweimüller (2009). Finally, Ryu et al. (2010) found that the changes in the South Korean quota system in 2001, increasing the subsidies to employers hiring targeted individuals with disabilities - specifically, those with severe disabilities and women with disabilities - led to a 4.7 percentage point decrease in the employment gap between individuals with and without disabilities.

The aim of this study is to add to the limited evaluation literature on quota systems by investigating to what extent the structural changes in

${ }^{6}$ Kruse and Schur, 2003; Hotchkiss, 2004. 
disability employment regulations that took place in South Korea in the middle of the 2000s affected the employment rate and subsequent job satisfaction of individuals with disabilities. Although the quota system in South Korea was adopted more than two decades ago, the system experienced substantial transformation between 2004 and 2006. Specifically, in 2004, the minimum size of employers who were obligated to comply with the quota system changed from 300 employees to 50 employees. This drastic change in the rules increased the number of available vacancies for individuals with disabilities in the whole South Korean labour market by approximately 20,000 units. $^{7}$ At the same time, subsidies to employers who employed above the required level of individuals with disabilities increased substantially in South Korea. ${ }^{8}$ Furthermore, at the beginning of 2006, the number of vacancies in the public sector for individuals with disabilities was substantially increased, by approximately 30,000 units, ${ }^{9}$ due to an increase in the number of jobs for which individuals with disabilities became eligible to apply. Previously, individuals with disabilities were ineligible to apply to certain positions in the public sector. Moreover, in 2006, companies with hazardous work environments (for example, mining, construction and security guard) were expected to start complying with the disability employment quota, whereas previously they were excluded from disability employment obligations or their employment quota was smaller than that for other companies. Also at the beginning of 2006, the penalties for not complying with the recommended rate for employing individuals with disabilities were substantially increased.

All these changes in the quota system have allegedly led to better employment situations among individuals with disabilities in South Korea. ${ }^{10}$ However, the effect of these changes in the quota system on the probability of employment (after controlling for selection into the labour market) has yet to be investigated. Unlike many studies in the literature, our study goes beyond simply studying the effect of new initiatives on the conditional probability of employment. We separate the effect of the changes in the quota system in South Korea into two effects: the effect on the probability of labour force participation and the effect on the unconditional probability of employment (after controlling for selection into the labour market). Our approach resembles the empirical strategy suggested by Hotchkiss (2004) in her inquiry into the effect of the ADA on the employment rate of individuals with disabilities. In separate analyses, we also investigate to what extent the changes in the quota system have improved the employment prospects of the more disabled segment of the population and whether the changes in the

\footnotetext{
${ }^{7}$ Yoo et al., 2010.

${ }^{8}$ Ryu et al., 2010.

${ }^{9}$ Yoo et al., 2010.

${ }^{10}$ Ryu et al., 2010.
} 
quota system are associated with increasing job satisfaction among all individuals with disabilities.

\section{Background on the South Korean quota system}

In South Korea, a number of laws have been signed in the last three decades to address unmet needs of individuals with disabilities. Table 1 summarises laws, amendments and changes in regulations related to the disability quota system in South Korea in the last three decades. The backbone of the South Korean disability employment doctrine was the adoption of the quota system in 1990 with the enactment of the Disability Employment Promotion Act. The objective of this new initiative was to advance employment and selfsufficiency among individuals with disabilities in South Korea. According to the new law, employers with at least 300 workers were obligated to ensure employees with disabilities composed at least 2.5 per cent of their workforce. Under the quota system, individuals register with a local government agency to obtain a certification of disability. This certification is then shared with the employer in the hiring process. Disability registration is not required, but an individual must register if he/she wants to receive several welfare benefits from government. Also, if an individual is not registered, he/she will not be considered by an employer and the government

TABLE 1

Laws, amendments and changes in regulations related to the disability quota system in South Korea

\begin{tabular}{|c|c|}
\hline$\overline{\text { Date }}$ & Description \\
\hline 13 January 1990 & $\begin{array}{l}\text { Enactment of the Disability Employment Promotion Act (DEPA). The } \\
\text { law introduced the quota system obligating employers with more than } \\
300 \text { employees to have a workforce with at least } 2.5 \text { per cent of } \\
\text { individuals having disabilities. }\end{array}$ \\
\hline 12 January 2000 & $\begin{array}{l}\text { Revision of the previous Act, changing the title of the Act to Disability } \\
\text { Employment Promotion and Vocational Rehabilitation Act. }\end{array}$ \\
\hline 29 January 2004 & $\begin{array}{l}\text { Minimum size of employers obligated to comply with the quota system } \\
\text { changed from } 300 \text { employees to } 50 \text { employees. }\end{array}$ \\
\hline 29 January 2004 & $\begin{array}{l}\text { Subsidies to employers who employed individuals with disabilities } \\
\text { beyond the specified level increased substantially. }\end{array}$ \\
\hline 1 January 2006 & $\begin{array}{l}\text { Penalties (subsidies) for not complying (complying) with the } \\
\text { recommended rate for employing individuals with disabilities increased } \\
\text { substantially. }\end{array}$ \\
\hline 1 January 2006 & $\begin{array}{l}\text { Number of companies obligated to employ disabled individuals } \\
\text { expanded. In 2006, companies with hazardous work environments (e.g. } \\
\text { mining, construction, security guard) were expected to start complying } \\
\text { with the disability employment quota. Furthermore, the number of } \\
\text { vacancies for individuals with disabilities was increased in the public } \\
\text { sector with the exception of police, safety and escort services. }\end{array}$ \\
\hline
\end{tabular}


as an individual with a disability in the disability employment rate calculation in the organisation.

The key feature of any employment quota system is a non-compliance tax. Any non-complier whose workforce does not meet the recommended rate for employing people with disabilities must pay a penalty for each nonemployed individual with a disability. In South Korea, the amount of this penalty per worker is calculated based on the average monthly cost that the average employer incurs for employing one individual with a disability. For example, in 2003, the penalty was set at the level of 437,000 KRW $(1,129 \mathrm{KRW}=1 \mathrm{USD})$ per worker per month and it has been steadily increasing since that year owing to steady inflation. In 2006, the South Korean government imposed additional penalties for the firms that either completely refused to comply with disability employment regulations or employed only half or less of the recommended level. In particular, if the workforce did not include any individuals with disabilities, the employer had to pay a penalty corresponding to the minimum wage amount in South Korea (700,600 KRW) for each non-employed individual with a disability. If the workforce included half or fewer of the recommended level of individuals with disabilities, in addition to the ordinary non-compliance tax for each non-employed worker, the employer had to pay an extra 255,000 KRW per worker per month.

To encourage further inclusion of individuals with disabilities in competitive employment, the South Korean government embedded into its employment quota system some financial incentives for the firms that employ above the recommended level of individuals with disabilities. This way, the South Korean government implicitly subsidises the wages of individuals with disabilities in such firms. Specifically, a firm that employs individuals with disabilities at a rate higher than officially required receives a monetary reward for each worker with a disability above the legal obligatory disability employment rate. The monetary reward could be even higher for employing either severely disabled individuals or females with disabilities. In 2003, the per-worker monetary reward was about $474,000 \mathrm{KRW}$. In 2004, the reward was increased by about 30 per cent.

The changes in the quota system from 2004 to 2006 are the focus of this paper. Two of the changes substantially increased the number of jobs available for individuals with disabilities. First, in 2004, the minimum size of employers who were obligated to comply with the employment quota decreased from 300 employees to 50 employees. Second, at the beginning of 2006, the types of occupations for which individuals with disabilities could be considered were broadened. This enabled individuals with disabilities to be hired for the majority of public jobs with the exception of police, safety and escort services. Furthermore, for individuals with disabilities, there was an increase in opportunities in hazardous sectors. At the beginning of 2006, 
there were two other changes to the system related to monetary incentives for employers: increased penalties for non-compliance with the quota system and increased rewards for surpassing the quota rate.

\section{Model}

The principal interest of this study is to understand whether the changes in the quota system between 2004 and 2006 had any impact on employment outcomes for individuals with disabilities in South Korea. Our empirical strategy is quite similar to the strategy employed by Hotchkiss (2004) in understanding the impact of the ADA legislation on labour market outcomes for individuals with disabilities in the US. Specifically, we assume that factors associated with the propensity to be in the labour force, $Y_{1 i}^{*}$, and the propensity to work, $Y_{2 i}^{*}$, can be modelled by the following binary response model with sample selection: ${ }^{11}$

$$
\begin{aligned}
& Y_{1 i}^{*}=\alpha_{11}+\gamma_{11}^{\prime} \mathbf{X}_{1 i}+\beta_{11} D_{i}+\varepsilon_{1 i} ; \\
& Y_{1 i}= \begin{cases}1 & \text { if } Y_{1 i}^{*}>0 \\
0 & \text { if } Y_{1 i}^{*} \leq 0 .\end{cases} \\
& Y_{2 i}^{*}=\alpha_{21}+\gamma_{21}^{\prime} \mathbf{X}_{2 i}+\beta_{21} D_{i}+\varepsilon_{2 i} ;
\end{aligned}
$$

$$
Y_{2 i}=\left\{\begin{array}{l}
1 \quad \text { if } Y_{1 i}^{*}>0 \text { and } Y_{2 i}^{*}>0 \\
0 \text { if } Y_{1 i}^{*}>0 \text { and } Y_{2 i}^{*} \leq 0 \\
- \text { if } Y_{1 i}^{*} \leq 0 .
\end{array}\right.
$$

In the above model, $\mathbf{X}_{1 i}$ and $\mathbf{X}_{2 i}$ are the individual characteristics that we believe to affect respectively an individual's labour force participation and employment decisions. The primary variable of interest is an indicator, $D_{i}$, of whether the individual has a disability. Finally, we assume that

$$
\begin{aligned}
& \varepsilon_{1 i} \sim N(0,1) ; \\
& \varepsilon_{2 i} \sim N(0,1) ; \\
& \operatorname{corr}\left(\varepsilon_{1 i}, \varepsilon_{2 i}\right)=\rho .
\end{aligned}
$$

The above expressions imply that to account for the fact that the employment decision is defined only if the individual participates in the labour force, we should allow for correlation of the normally distributed error terms across two equations. The above relationship between two

\footnotetext{
${ }^{11}$ Wooldridge, 2010.
} 
outcome equations is also known as a bivariate probit with selection. We estimate jointly equations (1) and (2) for each year from 2003 to 2007. To compute the marginal effect of disability on labour force participation and employment decisions, we compute predicted employment and labour force participation probabilities for the entire sample, varying the disability index in the sample between 0 and 1. This method, discussed by Cameron and Trivedi (2010, p. 343), allows one to compute a measure of the effect of a discrete change in a dummy variable such as disability on the probability of a certain event. After averaging the predicted probabilities separately for two different values of the disability index, we then plot the data points in one graph to track visually any changes in employment and labour force participation patterns in South Korea among individuals with disabilities after major changes in the disability quota system between 2004 and 2006.

For the purpose of identification, equation (1) modelling individuals' labour force participation decisions should have at least one variable that is not in equation (2) describing individuals' employment decisions. Similar to Hotchkiss (2004), we use 'non-labour income' as an exclusion restriction to identify the parameters of a binary response model with sample selection. Other than this exclusion restriction variable, $\mathbf{X}_{1 i}$ and $\mathbf{X}_{2 i}$ include the same variables: age, age squared, self-reported health, gender, marital status, education, province unemployment rate and region fixed effects. We group provinces into the five main regions based on GDP per capita data. Specifically, the first region includes the provinces with GDP per capita below 25,000 USD. Then, for the subsequent regions, we increase GDP per capita incrementally by 10,000 USD. The fifth region, which represents the region with GDP per capita above 55,000 USD, is actually represented by the single province, Ulsan.

To conduct a robustness check, we also estimate the bivariate probit model with selection pooling all years of data together. We introduce year fixed effects using the calendar year 2003 as a reference year. By crossmultiplying the newly-constructed year fixed effects with the disability indicator, this should allow us to test whether the employment and labour force participation probabilities for individuals with disabilities are substantially changed relative to the probabilities for non-disabled counterparts after the changes in the quota system. This approach is also known as a 'difference-in-difference' approach. Taking into account the longitudinal aspect of the data, the observations corresponding to the same individual within the pooled sample will inevitably be correlated, leading to inefficient point estimates. To address this statistical issue, we estimate the bivariate probit model with selection using the pooled sample with clusterrobust standard errors.

The structure of the longitudinal survey used in this study enables identification of multiple disabling conditions. This facilitates an 
investigation of the extent to which the severity of the disabling condition affects the employment prospects of the typical disabled individual before and after changes in the quota system in South Korea. Also, most importantly, the availability of multiple measures of disability creates an opportunity to test directly the relative importance of subsidies for the employment prospects of the typical individual with a disability. For example, if subsidies do not have any direct implications for the employment prospects of individuals with disabilities, then changes in the level of employment should not vary substantially across individuals with different severities of disability. If the level of subsidies has an effect on firms' employment strategies, then individuals with more severe disabilities may have a higher chance of finding employment after an increase in the level of subsidy. The alternative conjecture is that the regulation somehow alters the individual's decision to register officially as a disabled worker to benefit from the increasing demand for disabled workers. To test this hypothesis, we estimate the bivariate probit model with selection controlling for a set of dummies indicating the number of disabling conditions - the variables that we use as a proxy for disability severity - and the interaction of this new set of variables with a time dummy identifying observations corresponding to 2006 and 2007, the years following the major changes in the quota system. The magnitude of the parameters associated with the interaction terms should increase with the number of disabling conditions to support the given hypothesis.

Finally, we perform a sub-analysis to understand whether, after the changes in the quota system, individuals with disabilities in South Korea perceive higher satisfaction with their current jobs, employers, wages, contents of performed work, etc. than individuals without disabilities. We hypothesise that due to a larger pool of available job vacancies generated by the changes in disability employment regulations, people with disabilities will have better employment opportunities and eventually move to less marginal employment arrangements after the major changes in the quota system. Furthermore, we conjecture that people with disabilities will experience a greater increase in job satisfaction than non-disabled peers. To document whether overall job satisfaction has improved among individuals with disabilities relative to non-disabled peers, we use a conventional chisquare test where we compare the proportions of individuals with disabilities who agreed or were satisfied with certain criteria of their employment across two years, 2003 and 2007. We perform a similar comparison test separately for the sample of individuals without disabilities.

A simple comparison of proportions across two years somewhat mimics a 'difference-in-difference' approach; however, in contrast to that approach, we do not control for other observed factors within a regression due to insufficient sample size. The insufficient sample size is an artefact of the low 
employment rate among individuals with disabilities, employed people with disabilities being the segment of the disabled population who responded to job satisfaction items. Therefore, we cannot disentangle the effects of the changes in the quota system from the effects of other factors in explaining changes in individuals' job satisfaction. Still, we believe that this simple sub-analysis combined with the findings of our main analysis should shed light on the changes in the overall employment situation for people with disabilities and their perception about the workplace and current jobs before and after the changes in the quota system in South Korea.

\section{Data}

The primary data source for this study is the Korean Labour and Income Panel Study (KLIPS). The KLIPS is a longitudinal survey that collects information on all family members of 5,000 urban households representing a random sample of the South Korean population. The survey is conducted annually and the same set of questions is asked of the same set of households repeatedly in each wave. The first wave of the survey was conducted in 1998 and, currently, the KLIPS includes 10 waves; the last publicly-available wave represents data for the year 2007.

Despite the fact that the first wave of the survey was conducted in 1998 and the respondents have been followed for 10 years, only since the sixth panel (2003) has the set of disability questions been included in the questionnaire. Therefore, the panels used in our research inquiry were limited to those from 2003 and onward. Unfortunately, the absence of disability identifiers in the first five waves of the survey limited our ability to verify empirically whether any observed changes in labour market fortunes of individuals with disabilities after 2003 were simply artefacts of the longterm trends in employment fortunes of individuals with disabilities in South Korea, trends which could be independent of the recent transformation in the quota system.

The KLIPS contains both household- and individual-level variables. The longitudinal aspect of the KLIPS enables one to observe not only changes in household composition, financial resources and consumption over time but also changes in individual-level information on income-earning, education and vocational training activities, health status, employer characteristics and individuals' self-rated satisfaction with work and life. This gives a unique opportunity for researchers to evaluate with better precision the effectiveness of a number of employment-related initiatives implemented in South Korea within the survey period.

The main objective of our study is to quantify the effect of the changes in the quota system parameters on the labour force participation and employment rates of individuals with disabilities relative to non-disabled 
counterparts. Keeping in mind that the drastic changes in the quota system occurred within a two-year window from early 2004 to the beginning of 2006 , to carry out the proposed before-after comparative analysis, we created an analytical sample of South Korean urban workers capturing their employment statuses along with individual-level and contextual characteristics for the period between 2003 and 2007, the years for which the disability statuses of respondents were observable in the survey. To avoid any simultaneity in employment, education and retirement decisions, we restricted our sample to workers who were over 25 but below 60 years of age in the first year of the study period, which is 2003. The average effective retirement age in South Korea was 70 years for men and 67 years for women in the study period. ${ }^{12}$ However, individuals become eligible for governmentprovided retirement benefits at age 60 . Therefore, we decided to restrict the age of respondents in the first observation to 60. Furthermore, we dropped observations for four individuals whose education status was missing.

Table 2 provides the detailed information about the way the key variables of interest were constructed in our study. The pivotal variable in our analysis is an indicator of whether a respondent has a disability. We constructed the disability indicator based on individuals' responses to a set of questions identifying the presence of any sensory or mental impairments, difficulties with activities of daily living (ADLs), difficulties with instrumental activities of daily living (IADLs) and any participation restrictions in outdoor activities. Specifically, the respondents who answered affirmatively to one of the disability-related questions in the 2003 panel were identified as disabled. This strategy left us with a time-invariant measure of disability that is identified at the time before major changes in the quota system actually took place in South Korea. Our empirical strategy is dictated by our expectation that an increase in the number of available positions in South Korea due to the new initiatives targeted at improving labour market outcomes for individuals with disabilities might have a positive impact on the likelihood of reporting a work-related disability in the survey. As a result, to avoid any potential simultaneity between reporting disability and employment, we identified the group of individuals with disabilities based only on their reporting of disability in the 2003 panel before any drastic changes in the parameters of the quota system. We dropped from the sample 622 individuals (out of 7,439) who did not report the presence of any disabling condition in the 2003 panel but who reported at least one condition in the later panels. This empirical approach limits our identification of the impact of the changes in the quota system to the impact on individuals who were disabled before the actual changes in the disability employment system and excludes the impact on individuals who acquired functional limitations or

${ }^{12} \mathrm{OECD}, 2014$.

(C) 2015 Institute for Fiscal Studies

Fiscal Studies $\ 2015$ Institute for Fiscal Studies 
TABLE 2

Construction of the key variables

\begin{tabular}{|c|c|c|}
\hline Variables & Description & $\begin{array}{l}\text { Type of } \\
\text { variable }\end{array}$ \\
\hline Disability & $\begin{array}{l}\text { Is visually, auditory or speech impaired } \\
\text { Has difficulty walking, climbing stairs, } \\
\text { lifting heavy objects } \\
\text { Has persistent difficulties in: learning, } \\
\text { remembering, concentrating; indoor } \\
\text { activities (dressing, bathing, etc.); outdoor } \\
\text { activities (shopping, going to the hospital } \\
\text { etc.) }\end{array}$ & $\begin{array}{c}\text { Binary } \\
\{0,1\}\end{array}$ \\
\hline In labour force & $\begin{array}{l}\text { Is recognised as working in the consolidated } \\
\text { employment variable ( } \mathrm{p}_{-} \text {0201) of KLIPS or } \\
\text { was searching for a job in the past month } \\
\text { and was able to work }\end{array}$ & $\begin{array}{l}\text { Binary } \\
\{0,1\}\end{array}$ \\
\hline Employed & $\begin{array}{l}\text { Is recognised as working in the consolidated } \\
\text { employment variable (p_0201) of KLIPS }\end{array}$ & $\begin{array}{c}\text { Binary } \\
\{0,1\}\end{array}$ \\
\hline Age & Aged between 25 and 60 in 2003 & Continuous \\
\hline Male & Reported being male & $\begin{array}{c}\text { Binary } \\
\{0,1\}\end{array}$ \\
\hline Elementary education & $\begin{array}{l}\text { Level of education is elementary schooling } \\
\text { or no schooling }\end{array}$ & $\begin{array}{l}\text { Binary } \\
\{0,1\}\end{array}$ \\
\hline Secondary education & $\begin{array}{l}\text { Level of education is lower or upper } \\
\text { secondary }\end{array}$ & $\begin{array}{l}\text { Binary } \\
\{0,1\}\end{array}$ \\
\hline Vocational education & $\begin{array}{l}\text { Level of education is a two-year college } \\
\text { degree or a vocational, technical or associate } \\
\text { degree }\end{array}$ & $\begin{array}{c}\text { Binary } \\
\{0,1\}\end{array}$ \\
\hline College education & $\begin{array}{l}\text { Level of education is university (four years } \\
\text { or more) or graduate school (masters or } \\
\text { doctoral) }\end{array}$ & $\begin{array}{c}\text { Binary } \\
\{0,1\}\end{array}$ \\
\hline Married & $\begin{array}{l}\text { Current marital status is married, with } \\
\text { spouse }\end{array}$ & $\begin{array}{c}\text { Binary } \\
\{0,1\}\end{array}$ \\
\hline Non-earned income & $\begin{array}{l}\text { Total individual pre-tax yearly earned } \\
\text { income subtracted from the sum of } \\
\text { household total earnings, interest from } \\
\text { savings in banks and other financial } \\
\text { institutions, net monthly rent, amount of } \\
\text { benefit from social insurance, basic } \\
\text { livelihood security benefits and some other } \\
\text { income }\end{array}$ & Continuous \\
\hline Province unemployment rate & $\begin{array}{l}\text { Official annual unemployment rate in the } \\
\text { respondent's province of residence (numbers } \\
\text { from the official website of Statistics Korea } \\
\text { for years between } 2003 \text { and } 2007 \text { inclusive) }\end{array}$ & Continuous \\
\hline Self-reported health & $\begin{array}{l}\text { Rates current health condition as excellent, } \\
\text { good, fair, poor or very poor }\end{array}$ & $\begin{array}{c}\text { Categorical } \\
\{1,2, \ldots, 5\}\end{array}$ \\
\hline Region & Region of residence & $\begin{array}{c}\text { Categorical } \\
\{1,2, \ldots, 5\}\end{array}$ \\
\hline
\end{tabular}


FIGURE 1

Disability prevalence in the analytical sample

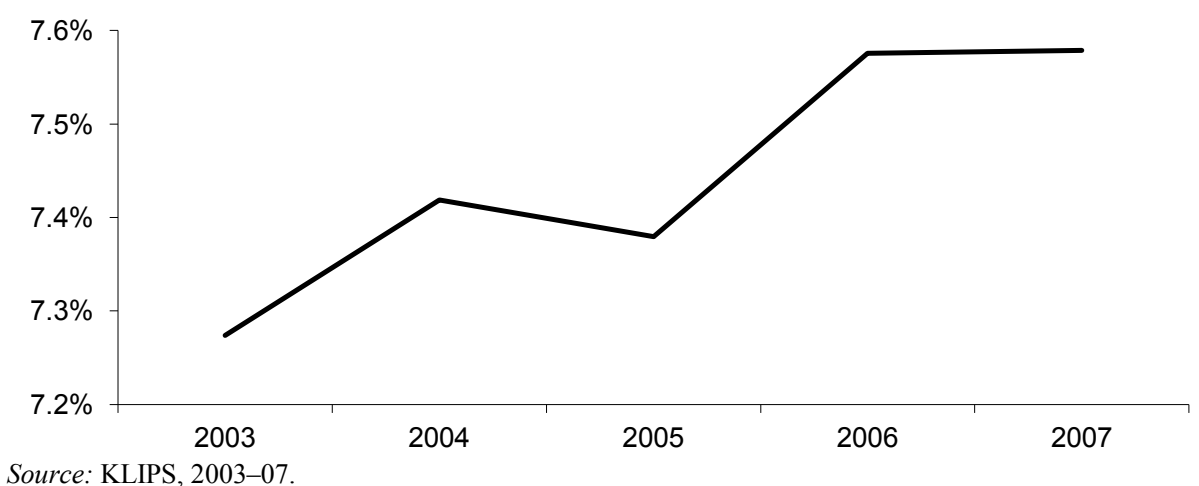

impairments after 2003. However, we still believe that our findings convey information about the labour market fortunes of the majority of individuals with disabilities in South Korea.

It is worth mentioning that the constructed disability indicator to some extent captures the conceptualisation of disability as outlined by the International Classification of Functioning, Disability and Health (ICF). According to the ICF, disability can be categorised into three broad concepts through the presence of any of: (1) health condition and impairment; (2) activity limitation; and (3) participation restriction. ${ }^{13}$ Our measure of disability shows that the prevalence of disability in our sample fluctuated between 7.3 and 7.6 per cent within the study period (see Figure 1). It should be noted that self-reported disability in the KLIPS does not match precisely the disability definition used by the quota system, which requires selfidentification at a local government office. The definition of disability used by government officials to identify disabled workers requires the presence of a substantial long-term impairment in daily or social life activity due to physical or mental disability. Specifically, the government standard defines a mental disability as 'a disability caused by a psychological development disorder or a mental disease' and a physical disability as 'a disability of principal external bodily functions or internal organs'. ${ }^{14}$

The KLIPS distinguishes between individuals who worked and those who did not work in the survey week. Employment status is given by a single variable constructed using different employment-related questions asked of each respondent in the individual questionnaire in each panel. However, for our analysis, it is crucial to identify not only respondents' employment status but also their labour force participation status. We use recommendations

\footnotetext{
${ }^{13}$ Hale, Hayghe and McNeil, 1998; Wittenburg and Nelson, 2006.

${ }^{14}$ Act on the Welfare of Persons with Disabilities, Article 2. 
given in the KLIPS user guides ${ }^{15}$ to construct the latter indicator. Specifically, we use the aforementioned consolidated employment variable to identify those who were employed at the time of the survey and add those who were involved in any active job-search activities up to one month before the survey or who identified themselves as able to work if any suitable position were available in the survey week. Using this strategy, we find that labour force participation has been slightly declining for individuals without disabilities for the period between 2003 and 2007 (from 75.1 per cent to 74.9 per cent) and increasing from 42.5 per cent to 45.1 per cent for individuals with disabilities (see Figure 2). This visual investigation of employment patterns provides evidence of certain changes in the labour force participation rate among individuals with disabilities relative to their nondisabled counterparts in South Korea after the changes in the quota system.

Unlike labour force participation, the unemployment rate among individuals with disabilities changed drastically after the major changes in the quota system from 2004 to 2006. Figure 3 shows that the unemployment rate for individuals with disabilities in our sample decreased from 9.3 per cent in 2003 to 5.5 per cent in 2007 and that the decline in the unemployment rate was steady across these years with the exception of 2006 when the unemployment rate increased relative to 2005. The figure also shows that the unemployment rate for individuals without disabilities decreased slightly after 2005, suggesting that other factors - possibly including macroeconomic factors - might be responsible for observed changes in the unemployment rate for individuals with disabilities.

FIGURE 2

Labour force participation rate in the analytical sample, by disability status

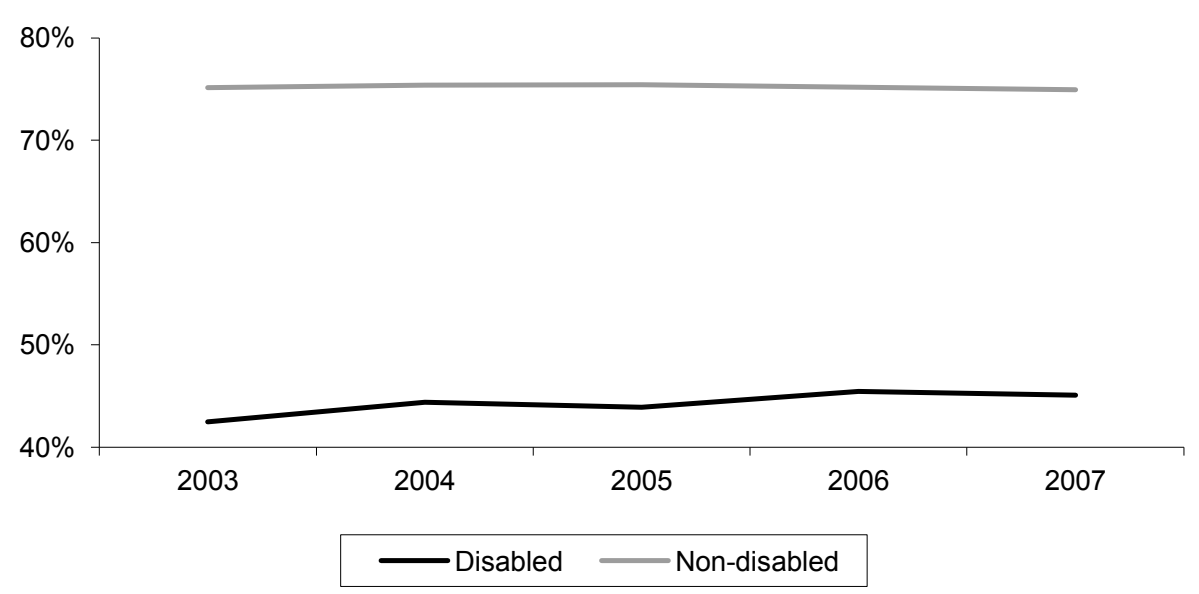

Source: KLIPS, 2003-07.

${ }^{15}$ Korean Labour Institute, 2013. 
FIGURE 3

Unemployment rate in the analytical sample, by disability status

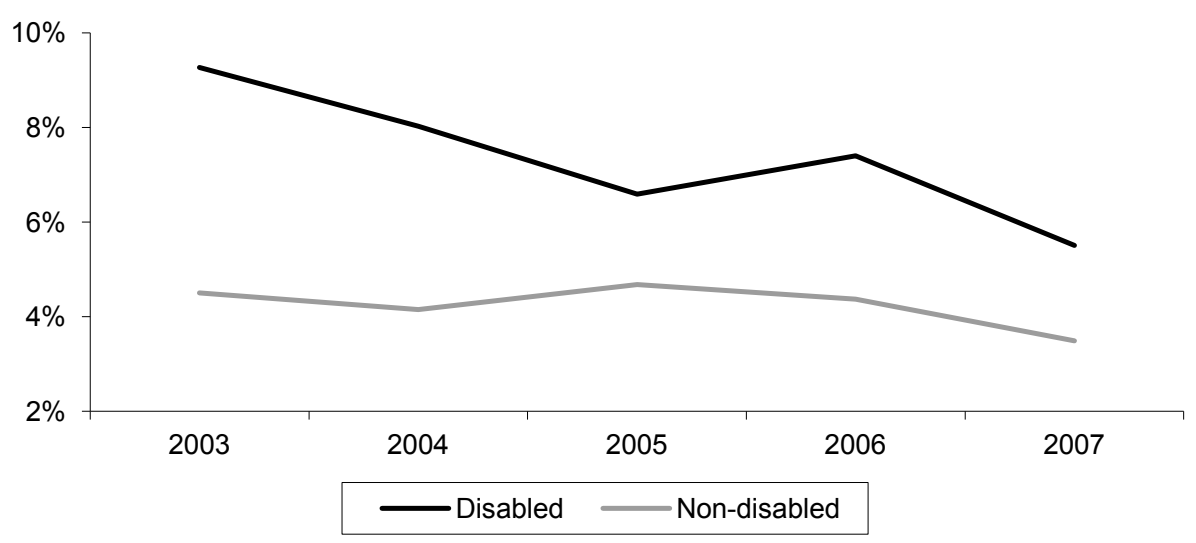

Source: KLIPS, 2003-07.

TABLE 3

Descriptive statistics for the analytical sample

\begin{tabular}{l|ccc}
\hline Variable & All & Disabled & Non-disabled \\
\hline In labour force & $72.90 \%$ & $44.23 \%$ & $75.21 \%$ \\
Employed & $95.61 \%$ & $92.63 \%$ & $95.75 \%$ \\
Self-reported health & 2.50 & 3.52 & 2.42 \\
Age & 43.06 & 50.18 & 42.49 \\
Male & $50.97 \%$ & $46.46 \%$ & $51.33 \%$ \\
Married & $79.89 \%$ & $67.84 \%$ & $80.86 \%$ \\
Province unemployment rate & $3.71 \%$ & $3.65 \%$ & $3.71 \%$ \\
Elementary education & $9.65 \%$ & $35.61 \%$ & $7.56 \%$ \\
Secondary education & $54.25 \%$ & $52.64 \%$ & $54.38 \%$ \\
Vocational education & $10.71 \%$ & $5.62 \%$ & $11.11 \%$ \\
College education & $25.39 \%$ & $6.13 \%$ & $26.94 \%$ \\
Region 1 & $44.73 \%$ & $42.66 \%$ & $44.89 \%$ \\
Region 2 & $44.78 \%$ & $43.92 \%$ & $44.85 \%$ \\
Region 3 & $5.97 \%$ & $8.85 \%$ & $5.74 \%$ \\
Region 4 & $2.30 \%$ & $2.99 \%$ & $2.24 \%$ \\
Region 5 & $2.22 \%$ & $1.57 \%$ & $2.27 \%$ \\
Non-earned income (log) & 2.21 & 2.21 & 2.21 \\
\hline
\end{tabular}

Note: 'Employed' is conditional on labour force participation. The unemployment rate of the analytical sample over the study period can be computed by subtracting the percentage of individuals 'employed' from 100 per cent. 'Province unemployment rate' is the average annual unemployment rate in the respondent's province of residence, obtained from Statistics Korea. 
Finally, in Table 3, we provide descriptive statistics on all variables used in our empirical inquiry broken down by disability status. The comparison of self-reported health across the two groups shows that the average person with a disability rates their health close to 'poor', while their non-disabled counterpart is more likely to rate their health as 'good' or 'fair'. ${ }^{16}$ The average individual with a disability is seven years older than their nondisabled counterpart, is less likely to be male ( 46.5 per cent versus 51.3 per cent) or married (67.8 per cent versus 80.9 per cent), is more likely to have the highest educational attainment as elementary education (35.6 per cent versus 7.6 per cent) and less likely to have vocational or college education (11.8 per cent versus 38.1 per cent), and has an identical log of non-earned income (both 2.2). The unemployment rate for the sample of individuals used in our analysis is 4.4 per cent (100 per cent minus the percentage of employed individuals conditional on labour force participation from Table 3 ), which is slightly above the official unemployment rate for the study period of 3.7 per cent ('Province unemployment rate' in the first column of Table 3). The minor discrepancy between the unemployment rate in the analytical sample and the official number can be explained by our sample selection strategy: only workers aged between 25 and 60 at the first interview were included in our sample, while the official number is calculated for all workers above 15 years old. ${ }^{17}$

\section{Results}

\section{Cross-sectional analysis}

As we outlined in Section III, the main empirical strategy of our analysis is to estimate separately for each year a binary response model of the individual's employment decision with initial selection into the labour force. Then, using the point estimates of the binary response model for the given year, we compute the predicted probabilities of labour force participation and employment, switching the disability index from 1 to 0 . Finally, we compute the averages of these probabilities and, combining the computed statistics with other years, we depict them in a single graph to observe the main trends in the predicted probabilities of employment and labour force participation between 2003 and 2007 for individuals with disabilities and then compare them with the probabilities computed for their non-disabled counterparts.

Figure 4 shows that after controlling for differences in observed characteristics and changes in labour market conditions, the predicted

\footnotetext{
${ }^{16} \mathrm{~A}$ higher value of self-reported health is an indicator of poorer health status.

${ }^{17}$ Statistics Korea, 2014.
} 
FIGURE 4

Simulated probabilities of employment (taking selection into the labour market into account) and labour force participation for disabled individuals

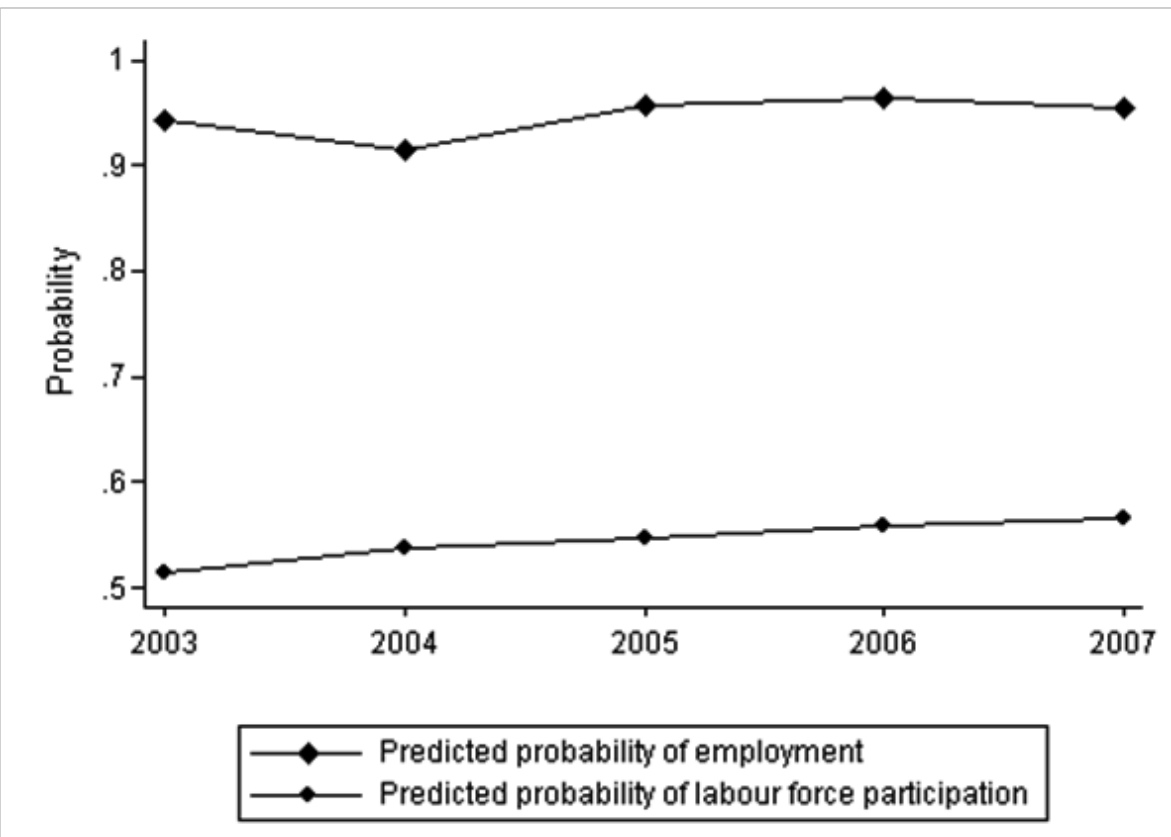

Note: The simulated employment probability is computed after taking selection into the labour market into account. Both probabilities are the averaged probabilities computed for the entire sample using the coefficients reported in Table 4 and actual values for independent variables included in $X_{i 1}$ and $X_{i 2}$.

Source: KLIPS, 2003-07.

probabilities of both employment and labour force participation for individuals with disabilities steadily increased after 2004. Specifically, the probability of employment (after controlling for selection into the labour market) increased from 91.6 per cent in 2004 to 95.4 per cent in 2007. Similarly, the predicted probability of labour force participation increased from 51.5 per cent in 2003 to 56.6 per cent in 2007 . These patterns in the data may serve as partial evidence that the labour market fortunes of individuals with disabilities may have improved in South Korea after the adoption of new employment incentives aimed at increasing the hiring and employment of targeted individuals in competitive settings.

To demonstrate that the changes in the quota system only affected individuals with disabilities, we then contrast the above probabilities with the probabilities computed for non-disabled counterparts. Figures 5 and 6 show that the predicted probabilities of employment (after controlling for selection into the labour market) and of labour force participation for individuals without disabilities did not change substantially in the study 
period: the labour force participation probability fluctuated around 75 per cent and the employment probability fluctuated around 96 per cent. In contrast, the predicted probabilities of labour force participation and of employment for people with disabilities, as discussed above, visually increased starting from 2004. These findings are compatible with our conceptual expectations: the changes in the quota system should not have any spillover effect on labour market opportunities for individuals without disabilities and should only affect the labour market fortunes of individuals with disabilities. However, based on this analysis, we are still unable to verify whether these observed improvements in labour force participation and employment (taking selection into the labour market into account) for individuals with disabilities are statistically significant relative to nondisabled counterparts. To answer this question, we performed the differencein-difference analysis with the pooled sample.

FIGURE 5

Simulated probability of labour force participation, by disability status

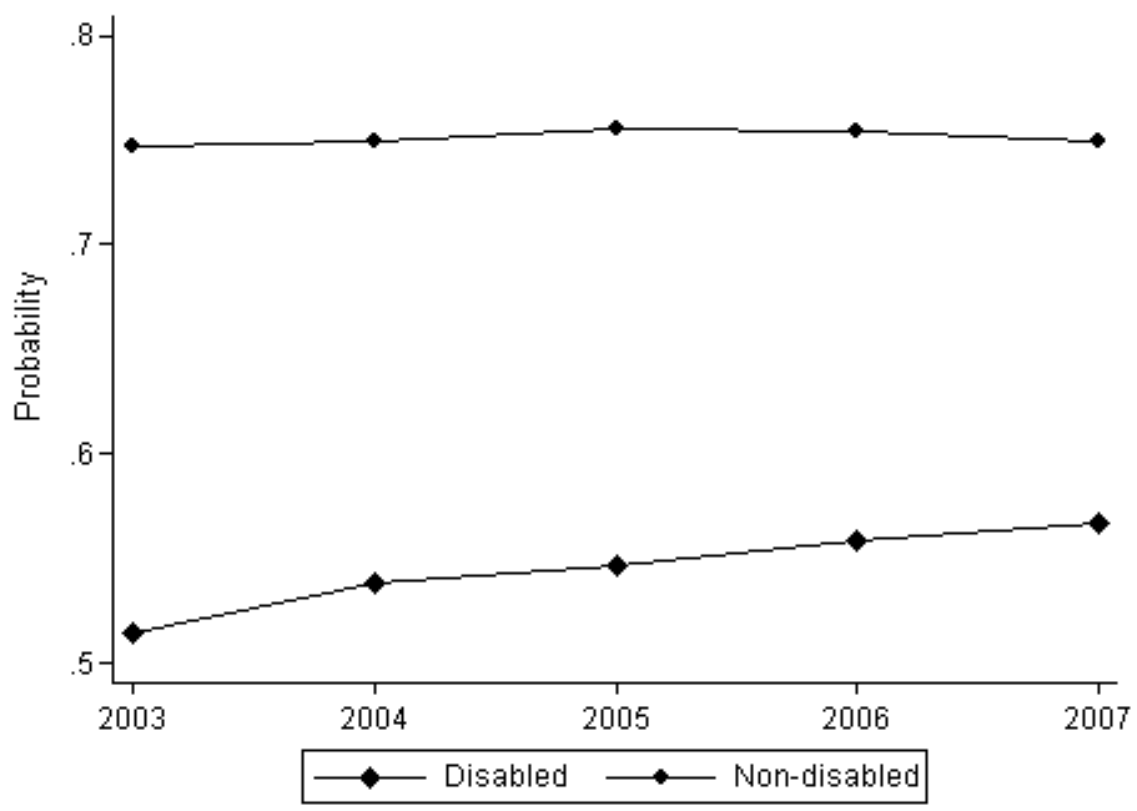

Note: The predicted probability of labour force participation is the averaged probability of labour force participation computed for each observation using coefficients reported in Table 4 and the actual values of independent variables in $X_{i 1}$ only varying the disability index between 0 and 1 .

Source: KLIPS, 2003-07. 
FIGURE 6

Simulated probability of employment (taking selection into the labour market into account), by disability status

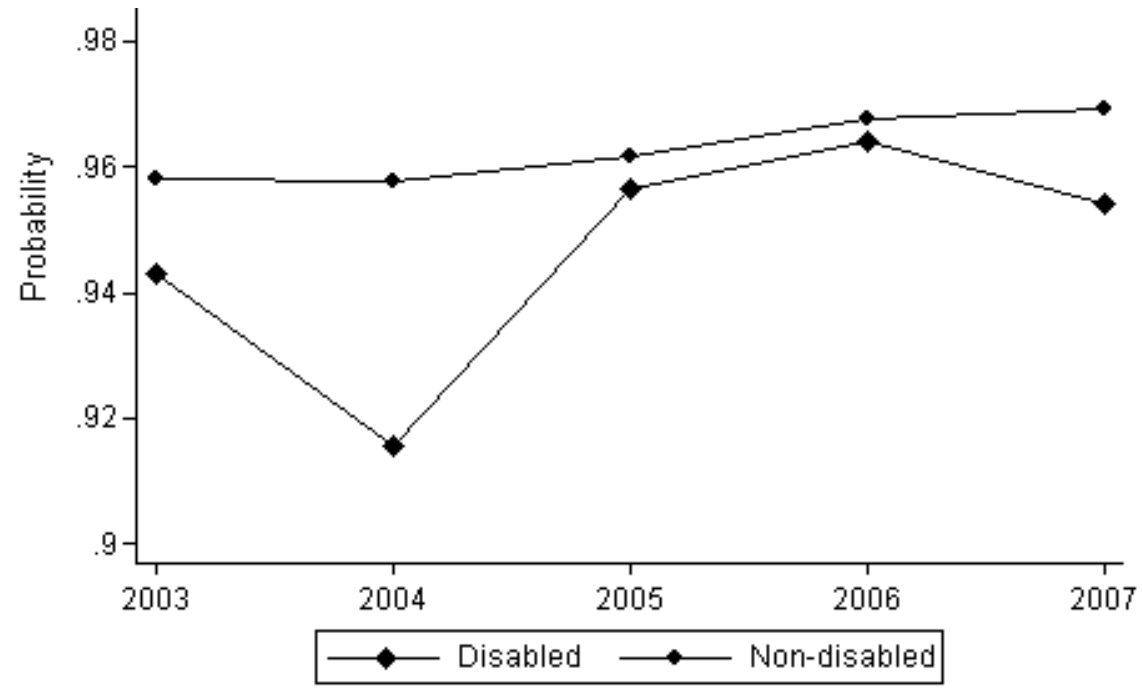

Note: The simulated employment probability is computed after taking selection into the labour market into account. The predicted probability of employment is the averaged probability of employment computed for each observation using coefficients reported in Table 4 and the actual values of independent variables in $X_{i 2}$ only varying the disability index between 0 and 1 .

Source: KLIPS, 2003-07.

\section{Difference-in-difference analysis with the pooled sample}

In this analysis, by pooling data for all years, within the bivariate probit model with selection, we estimated the effect of disability on labour force participation and employment and the interactions of the disability indicator with year fixed effects. The statistical significance of these interaction terms for the years after the major changes in the quota system should provide us with evidence of whether the changes in labour market outcomes for individuals with disabilities after the changes in the quota system were substantial relative to those of their non-disabled counterparts. Results reported in Table 4 show that the probability of labour force participation increased steadily from 2003 with statistically significant results only for 2006 and 2007. At the same time, while the probability of employment also increased for individuals with disabilities relative to their non-disabled counterparts in the years after 2003, those changes in the employment probability were not statistically significant at any conventional levels. 
TABLE 4

Results of bivariate probit model with selection

\begin{tabular}{l|rrr|rrr}
\hline Variable & \multicolumn{3}{|c|}{ Labour force participation } & \multicolumn{4}{|c}{ Employment } \\
& Coeff. & Std error & z-stat. & Coeff. & Std error & z-stat. \\
\hline Socio-demographic characteristics & & & & & & \\
Age & $0.249^{* * *}$ & 0.015 & 16.43 & $0.041^{*}$ & 0.021 & 1.95 \\
Age squared & $-0.003^{* * *}$ & 0.000 & -16.32 & 0.000 & 0.000 & -1.44 \\
Self-reported health & $-0.204^{* * *}$ & 0.017 & -12.18 & -0.041 & 0.026 & -1.61 \\
Male & $1.184^{* * *}$ & 0.033 & 35.84 & 0.006 & 0.050 & 0.11 \\
Married & $-0.202^{* * *}$ & 0.042 & -4.78 & $0.319^{* * *}$ & 0.046 & 7.00 \\
Log of non-earned income & $-0.066^{* * *}$ & 0.008 & -8.08 & & & \\
Unemployment rate & -0.025 & 0.021 & -1.17 & -0.016 & 0.026 & -0.62 \\
Educational group & & & & & & \\
(elementary is the reference group) & & & & & & \\
Secondary & $-0.272^{* * *}$ & 0.061 & -4.47 & -0.062 & 0.072 & -0.86 \\
Vocational & $-0.267^{* * *}$ & 0.079 & -3.37 & -0.044 & 0.091 & -0.48 \\
College & $-0.215^{* * *}$ & 0.073 & -2.95 & $0.184^{* *}$ & 0.086 & 2.14 \\
Region & & & & & & \\
(region 1 is the reference group) & & & & & & \\
Region 2 & $0.109^{* * *}$ & 0.032 & 3.36 & 0.023 & 0.038 & 0.61 \\
Region 3 & 0.091 & 0.071 & 1.27 & $0.170^{*}$ & 0.093 & 1.83 \\
Region 4 & $0.198^{* *}$ & 0.096 & 2.07 & $0.243^{*}$ & 0.133 & 1.83 \\
Region 5 & 0.055 & 0.099 & 0.56 & $0.582^{* * *}$ & 0.140 & 4.14 \\
Disability indicator and its & & & & & & \\
interactions with year fixed effects & & & & & & \\
Disability & $-0.805^{* * *}$ & 0.074 & -10.95 & -0.216 & 0.134 & -1.61 \\
Year 2004 $\times$ Disability & 0.019 & 0.057 & 0.33 & 0.023 & 0.183 & 0.13 \\
Year 2005 $\times$ Disability & 0.043 & 0.069 & 0.62 & 0.156 & 0.193 & 0.81 \\
Year 2006 $\times$ Disability & $0.140^{*}$ & 0.075 & 1.89 & 0.070 & 0.184 & 0.38 \\
Year 2007 $\times$ Disability & $0.194^{* * *}$ & 0.076 & 2.56 & 0.095 & 0.197 & 0.48 \\
Constant & $-3.926^{* * *}$ & 0.324 & -12.10 & 0.587 & 0.454 & 1.29 \\
$\rho$ (correlation of errors) & $-0.223^{* * *}$ & 0.078 & -2.86 & & & \\
No. of observations & & & & & & \\
N & & & 30,233 & & \\
\hline
\end{tabular}

Note: Year fixed effects are also included in the set of covariates. The statistic of the Wald test, which tests the level of independence of the equations, is 7.66 with p-value $<0.01$, implying that the two equations are not independent. * indicates statistically significant at 10 per cent level, ${ }^{* *}$ statistically significant at 5 per cent level and $* * *$ statistically significant at 1 per cent level.

Taking into consideration the findings of the two separate analyses, we end up with mixed evidence about the effectiveness of the new initiatives in disability employment policy for the labour market fortunes of individuals with disabilities in South Korea. On the one hand, we observe a visual increase in both labour force participation and employment rates (after controlling for selection into the labour market) for the representatives of the targeted group of the population. On the other hand, the improvement in labour force participation for individuals with disabilities is only translated 
into a marginal improvement in the probability of employment (after taking selection into the labour market into account) relative to their non-disabled counterparts.

\section{Severity of disability and employment outcomes}

One of the goals of this paper is to evaluate the importance of subsidies in disability employment policy in South Korea and their impact on the employment outcomes of individuals with disabilities. Despite the fact that the main aim of subsidies is to create incentives for employers to hire more disabled individuals regardless of the severity of the disabling conditions, one of the criticisms of the quota system is that it actually fails to improve the labour market fortunes of the most severely disabled individuals. We implicitly test whether the level of subsidy in South Korea is adequate and generates better employment outcomes not only among individuals with disabilities in general, but also for those who have more severe disabilities.

In Table 5, we report the results of a bivariate probit model with selection that incorporates severity of disability as measured by the number of affirmative responses to the three different disability questions reported in Table 2. Specifically, the number of disabilities (ranging from zero to three) is entered in the model in the form of indicators, with the absence of any disability as the reference group, and interacted with a time dummy identifying observations for years 2006 and 2007. Our earlier analysis shows that the largest effects occurred during these two years, the years after major changes in the quota system in South Korea took place. The results in Table 5 suggest that the labour force participation rate for those with one reported condition increased relative to that for non-disabled counterparts. Moreover, individuals with two reported conditions experienced a larger increase in labour force participation rate compared with individuals with a single condition, suggesting that the level of subsidies may have a larger impact on labour force participation for this group of individuals with more severe disabilities. As predicted by critics of the quota system, the labour force participation rate of the most disabled individuals - those who reported all three disabling conditions - did not change much relative to their nondisabled counterparts. Finally, relative to individuals with no disabling conditions, the employment prospects of any of the disability groups did not change after 2005 .

These findings may imply that although firms in South Korea have incentives to generate extra revenue by using a more disabled workforce, they may still be unwilling to accommodate severely disabled individuals or may have certain negative stereotypes about their ability to work and be productive entities in the workplace, suggesting that the quota system in 
TABLE 5

Results of bivariate probit model with selection

\begin{tabular}{l|ccc|ccr}
\hline Variable & \multicolumn{3}{|c|}{$\begin{array}{c}\text { Labour force participation } \\
\text { Coeff. }\end{array}$} & \multicolumn{4}{|c}{ Etd error } & z-stat. & Coeff. & Std error & z-stat. \\
\hline $\begin{array}{l}\text { No. of disabling conditions (zero } \\
\text { conditions is the reference group) }\end{array}$ & & & & & & \\
$\begin{array}{l}\text { and interactions with 2006 and } \\
\text { 2007 year fixed effect }\end{array}$ & & & & & & \\
One condition & $-0.575^{* * *}$ & 0.077 & -7.44 & -0.075 & 0.107 & -0.70 \\
Two conditions & $-1.066^{* * *}$ & 0.117 & -9.12 & $-0.420^{* *}$ & 0.163 & -2.57 \\
Three conditions & $-1.817^{* * *}$ & 0.252 & -7.21 & -0.323 & 0.339 & -0.95 \\
After 2005 & 0.010 & 0.018 & 0.54 & 0.019 & 0.035 & 0.53 \\
One condition $\times$ After 2005 & $0.113^{*}$ & 0.062 & 1.82 & 0.078 & 0.161 & 0.48 \\
Two conditions $\times$ After 2005 & $0.315^{* * *}$ & 0.113 & 2.78 & -0.067 & 0.209 & -0.32 \\
Three conditions $\times$ After 2005 & 0.048 & 0.148 & 0.32 & 0.236 & 0.576 & 0.41 \\
\hline
\end{tabular}

Note: Year fixed effects are also included in the set of covariates. * indicates statistically significant at 10 per cent level, ${ }^{* *}$ statistically significant at 5 per cent level and ${ }^{* * *}$ statistically significant at 1 per cent level.

reality fails to improve the employment prospects of severely disabled individuals.

\section{Job satisfaction in 2003 and 2007}

Finally, we investigated the changes in job satisfaction for individuals with disabilities relative to their non-disabled counterparts within a parsimonious analysis. In each wave, all employed KLIPS respondents respond to the block of job satisfaction questions. Based on the responses of individuals with disabilities, we constructed 15 binary variables indicating whether a particular individual with a disability strongly agrees or agrees with a certain statement related to his/her current job or is strongly satisfied or satisfied with a certain condition in his/her current job. The description of all the job satisfaction questions is given in Table 6 along with results from the statistical analysis. In the non-parametric analysis, we compared the percentage of strongly agree / agree or strongly satisfied / satisfied responses given by working individuals with disabilities in 2003, with the equivalent percentage of responses given in 2007 , after the full introduction of all the new disability employment regulations. The simple before-andafter comparison shows that individuals with disabilities responded more affirmatively to all job satisfaction questions in 2007 than in 2003. Specifically, we found that more individuals with disabilities were enjoying their jobs in 2007 than in 2003 ( 36 per cent versus 28 per cent). About 25 per cent of employed individuals with disabilities reported in 2007 that they were satisfied with their working hours, which is almost 10 percentage 
TABLE 6

Overall job satisfaction before and after the changes in the quota system

\begin{tabular}{|c|c|c|c|c|c|c|c|c|c|}
\hline \multirow[t]{2}{*}{ Description } & \multicolumn{4}{|c|}{ With disability } & \multicolumn{4}{|c|}{ Without disability } & \multirow{2}{*}{$\begin{array}{l}\text { Difference-in- } \\
\text { difference }\end{array}$} \\
\hline & 2003 & 2007 & Difference & $\chi^{2}$ & 2003 & 2007 & Difference & $\chi^{2}$ & \\
\hline I'm satisfied with the job I'm currently doing & 0.242 & 0.299 & 0.057 & 1.57 & 0.401 & 0.429 & $0.028 * *$ & 6.60 & 0.029 \\
\hline I'm glad to have joined this company & 0.368 & 0.385 & 0.017 & 0.11 & 0.509 & 0.466 & $-0.043 * * *$ & 15.36 & 0.060 \\
\hline I enjoy this job & 0.284 & 0.364 & $0.079^{*}$ & 2.72 & 0.446 & 0.453 & 0.007 & 0.44 & 0.072 \\
\hline I feel this job to be personally rewarding & 0.300 & 0.342 & 0.042 & 0.77 & 0.408 & 0.400 & -0.008 & 0.55 & 0.050 \\
\hline $\begin{array}{l}\text { I want to continue this job if other things } \\
\text { remain the same }\end{array}$ & 0.474 & 0.599 & $0.125^{* *}$ & 5.94 & 0.585 & 0.622 & $0.037 * * *$ & 11.74 & $0.088^{*}$ \\
\hline Satisfied with wages & 0.058 & 0.091 & 0.033 & 1.49 & 0.143 & 0.157 & $0.014^{*}$ & 3.21 & 0.019 \\
\hline Satisfied with stability of employment & 0.206 & 0.251 & 0.045 & 1.08 & 0.343 & 0.396 & $0.053 * * *$ & 24.57 & -0.008 \\
\hline Satisfied with content of the work & 0.232 & 0.299 & 0.068 & 2.23 & 0.380 & 0.422 & $0.042 * * *$ & 15.10 & 0.026 \\
\hline Satisfied with work environment & 0.184 & 0.214 & 0.030 & 0.52 & 0.281 & 0.330 & $0.049 * * *$ & 23.35 & -0.019 \\
\hline Satisfied with work hours & 0.153 & 0.251 & $0.099 * *$ & 5.71 & 0.284 & 0.334 & $0.049 * * *$ & 23.17 & 0.050 \\
\hline $\begin{array}{l}\text { Satisfied with possibility of personal } \\
\text { development }\end{array}$ & 0.163 & 0.187 & 0.024 & 0.38 & 0.238 & 0.265 & $0.027 * * *$ & 7.74 & -0.003 \\
\hline $\begin{array}{l}\text { Satisfied with communication or personal } \\
\text { relationships }\end{array}$ & 0.247 & 0.289 & 0.041 & 0.82 & 0.325 & 0.372 & $0.047 * * *$ & 19.72 & -0.005 \\
\hline Satisfied with fairness of promotion & 0.080 & 0.094 & 0.014 & 0.13 & 0.156 & 0.191 & $0.035 * * *$ & 11.50 & -0.020 \\
\hline Satisfied with corporate welfare & 0.050 & 0.065 & 0.015 & 0.23 & 0.149 & 0.187 & $0.038 * * *$ & 14.42 & -0.023 \\
\hline Satisfied with main job & 0.175 & 0.222 & 0.047 & 1.30 & 0.258 & 0.312 & $0.054 * * *$ & 29.83 & -0.007 \\
\hline
\end{tabular}


points higher than in the 2003 panel. With respect to willingness to stay with their current employers if other things remain the same, 60 per cent of individuals with disabilities responded affirmatively to this question in 2007, a 13 percentage point difference from 2003. Finally, although these are not statistically significant differences, more people with disabilities were satisfied with their current and/or main job, the stability of employment, content of the work, work environment and personal relationships in their current workplaces and felt their job to be personally rewarding in 2007 than in 2003.

Further, we examined whether the given improvements in job satisfaction for individuals with disabilities were significant relative to changes in job satisfaction for individuals without disabilities. We found that, in general, there were no significant differences between the responses of individuals with and without disabilities to the job satisfaction questions between 2003 and 2007, with the exception of one statistically significant trend: individuals with a disability had a larger change in rating for the item 'I want to continue this job if other things remain the same'. The findings of this parsimonious analysis demonstrate that the new regulations in the quota system in South Korea might have no impact on disabled individuals' job satisfaction relative to their non-disabled counterparts.

\section{Conclusion}

Further expanding the disability policy literature, this study exploits the structural changes in South Korea's disability employment quota system in 2004 and 2006 in order to understand their impact on the prospect of employment and on job satisfaction for individuals with disabilities. Our results show that starting from 2004, relative to non-disabled counterparts, labour force participation among individuals with disabilities has improved; however, this finding may be part of a longer-term trend in people's labour market fortunes that we cannot observe using these data. Meanwhile, the probability of employment (after controlling for selection into the labour market) among this segment of the population has shown some improvement, but the observed improvement has not been substantial relative to non-disabled counterparts. Furthermore, our results show that in 2007 as compared with 2003 (prior to the changes in the quota system), individuals with disabilities reported being more satisfied with their jobs; however, the increases in job satisfaction were about the same as those reported by individuals without disabilities. In fact, for certain work characteristics, the evidence points toward smaller increases in job satisfaction during the study period among the individuals with disabilities. Taken together, our findings may suggest that additional opportunities, available as a result of increasing (1) the number of employers covered by 
the quota system, (2) the number of jobs available to individuals with disabilities and (3) the financial incentives for employing individuals with disabilities, have increased the labour force participation of people with disabilities in South Korea relative to their non-disabled counterparts. However, these opportunities have had limited positive impact on the probability of employment (after controlling for selection into the labour market) and on job satisfaction.

The major shortcomings of the quota system in South Korea have been extensively discussed in the literature. First, Chun and Yi (2002) surmise that the improvement in employment opportunities for individuals with disabilities in South Korea primarily affect the less severely disabled population, ignoring the needs and desires of the most disabled subpopulation. We find evidence that the labour force participation rate may have increased more for people with more severe disabilities; however, the most severely disabled individuals' labour force participation remained unchanging even after the introduction of substantial incentives to hire individuals with disabilities. This latter finding somewhat confirms the earlier criticism of the quota system in South Korea.

Second, Kim (2010) points out that 'the compulsory hiring of persons with disabilities will be more effective when an anti-discrimination policy and an equal employment opportunity policy are more deliberately devised and strictly implemented with accommodation provisions'. Our analysis shows that only 21 per cent of employed individuals with disabilities reported being satisfied with their work environment in 2007, which is only a 3 percentage point improvement after the adoption of new incentives and which lags the similar statistic for their non-disabled counterparts by 12 percentage points. First, it should be a concern of South Korean policymakers that a substantial gap exists in the level of satisfaction with the work environment between the two groups of individuals. Furthermore, after the introduction of the new initiatives, disabled individuals' satisfaction with their work environment improved at a lower rate than the rate of improvement experienced by non-disabled counterparts. This suggests that the observed increase in job satisfaction among individuals with disabilities was part of the overall improvement of work environments in South Korea and not related to the recent changes in the quota system. Therefore, if the goal of the South Korean government is to improve workplace experience along with employment prospects of individuals with disabilities relative to non-disabled counterparts, the recent quota system initiatives could be complemented with employer education around employment nondiscrimination, workplace inclusion, disability awareness and reasonable accommodation.

Finally, Kim (2010) stresses the existence of only a short-term effect of the quota system on employment prospects for individuals with disabilities, 
without any longer-term improvements. Unfortunately, we only had data covering two years after the major changes in the quota system took place, limiting our ability to quantify the longer-term effects of the new disability employment initiatives. Furthermore, due to the unavailability of disability indicators prior to 2003, in this study we were not able to test whether the observed improvement in labour force participation among individuals with disabilities was part of longer-term trends in the labour market fortunes of this segment of the population in South Korea. Overall, despite the limitations of our current data source, we can conclude from our findings that the new disability employment initiatives did not have a major impact on the disability employment situation in South Korea.

As the US and other countries consider their own disability employment situations, they can learn from studies such as this one on the effectiveness of quota systems. To better understand the impact in a country's own unique context, it is possible to 'test out' such a system. For example, in the US, a quota-like system is being implemented for a select group of employers. Specifically, the US Office of Federal Contract Compliance Programmes recently released regulations updating Section 503 of the Rehabilitation Act of 1973, adding a disability employment 'utilisation goal' for businesses with federal contracts or subcontracts. Federal contractors will be required to invite applicants and employees regularly to self-identify as an individual with a disability. Employers will need to track these data and their progress toward meeting a utilisation goal of 7 per cent across job categories. These changes move toward a quota system, although the system does not have the financial incentives of the South Korean and other quota systems. The results of our study suggest that such incentives may have some limited positive impact on labour force participation and the labour market fortunes of people with disabilities.

\section{References}

Acemoglu, D. and Angrist, A. (2001), 'Consequences of employment protection? The case of the Americans with Disabilities Act', Journal of Political Economy, vol. 109, pp. 915-57.

Beegle, K. and Stock, W. (2003), 'The labor market effects of disability discrimination laws', Journal of Human Resources, vol. 38, pp. 806-59.

Bell, D. and Heitmueller, A. (2005), 'The Disability Discrimination Act in the UK: helping or hindering employment amongst the disabled?', Institute for the Study of Labor (IZA), Discussion Paper no. 1476.

Braddock, D. (2010), Public Spending for Disability in the United States: 1997-2006, Boston, MA: Federal Reserve Bank of Boston. Proceedings from a conference on housing for people with disabilities held on 4-5 February 2010, at the Federal Reserve Bank of the United States, Washington DC.

Cameron, C. and Trivedi, P. (2010), Microeconometrics Using Stata, revised edition, College Station, TX: Stata Press. 
Chun, Y-P. and Yi, K. (2002), 'Interpreting the implementation process of employment policy for the disabled by means of a policy sailing and anchoring effect metaphor', Korean Public Administration Review, vol. 36, pp. 60-76 (in Korean).

DeLeire, T. (2000), 'The wage and employment effects of the Americans with Disabilities Act', Journal of Human Resources, vol. 35, pp. 693-715.

Erickson, W., Lee, C. and von Schrader, S. (2012), 2011 Disability Status Report: United States, Ithaca, NY: Cornell University Employment and Disability Institute (EDI).

Hale, T., Hayghe, H. and McNeil, J. (1998), 'Persons with disabilities: labor market activity, 1994', Monthly Labor Review, vol. 121, no. 9, pp. 3-12.

Hotchkiss, J. (2004), 'A closer look at the employment impact of the Americans with Disabilities Act', Journal of Human Resources, vol. 39, pp. 887-911.

Jolls, C. and Prescott, J. (2004), 'Disaggregating employment protections: the case of disability discrimination', National Bureau of Economic Research (NBER), Working Paper no. 10740.

Kim, C-K. (2010), 'Comparative perspectives on disability employment policy', International Review of Public Administration, vol. 15, no. 3, pp. 27-35.

Korean Labour Institute (2013), User's Guide: Korean Labour and Income Panel Study (KLIPS), Waves 1-10. Retrieved from http://www.kli.re.kr/klips/en/about/introduce.jsp.

Kruse, D. and Schur, L. (2003), 'Employment of people with disabilities following the ADA', Industrial Relations, vol. 42, pp. 31-66.

Lalive, R., Wuellrich, J-P. and Zweimüller, J. (2009), 'Do financial incentives for firms promote employment of disabled workers? A regression discontinuity approach', Centre for Economic Policy Research (CEPR), Discussion Paper no. 7373.

Lechner, M. and Vazquez-Alvarez, R. (2003), 'The effect of disability on labour market outcomes in Germany: evidence from matching', Institute for the Study of Labor (IZA), Discussion Paper no. 967.

OECD (2009), 'Sickness, disability and work: keeping on track in the economic downturn', Background Paper, High-Level Forum, Stockholm, 14-15 May 2009.

- (2014), 'Ageing and employment policies: statistics on average effective age of retirement', http://www.oecd.org/employment/emp/ageingandemploymentpoliciesstatisticsonaverageeffectiveageofretirement.htm, accessed 7 February 2014.

Ryu, J., Jun, Y., Nam, Y. and Park, C. (2010), Evaluation of Disability Employment Policy in Korea and Future Strategies, Employment Development Institute, Korea Employment Agency for the Disabled (KEAD).

Statistics Korea (2014), 'Statistical terms: unemployment rate \& economically active population'.

Verick, S. (2004), 'Do financial incentives promote the employment of the disabled?', Institute for the Study of Labor (IZA), Discussion Paper no. 1256.

Wittenburg, D. and Nelson, S. (2006), A Guide to Disability Statistics from the Survey of Income and Program Participation, Disability Statistics User Guide Series, Ithaca, NY: Rehabilitation Research and Training Center on Disability Demographics and Statistics, Cornell University.

Wooldridge, J. (2010), Econometric Analysis of Cross Section and Panel Data, second edition, Cambridge, MA: MIT Press.

Wuellrich, J-P. (2010), 'The effects of increasing financial incentives for firms to promote employment of disabled workers', Economics Letters, vol. 107, pp. 173-6.

Yoo, W., Jang, C., Kim, Y., Byeon, M., Hong, J. and Yoon, H. (2010), The Evolution of Disability Employment Policy and a Development Direction for the Mandatory Employment System in Korea, Employment Development Institute, Korea Employment Agency for the Disabled (KEAD). 